\title{
Atmospheric-Pressure Plasma Spray Deposition of Silver/HMDSO Nanocomposite on Polyamide 6,6 with Controllable Antibacterial Activity
}

By A. I. Ribeiro, University of Minho, Guimarães, Portugal; M. Modic and U. Cvelbar, Jožef Stefan Institute, Ljubljana, Slovenia; G. Dinescu and B. Mitu, National Institute for Lasers, Plasma and Radiation Physics, Măgurele, Romania; A. Nikiforov, C. Leys, and I. Kuchakova, Ghent University, Ghent, Belgium; and A. P. Souto and A. Zille, University of Minho Paper presented at the ICON2019 conferences in Çorlu, Tekirdağ, Turkey April 17-19, 2019.

\section{Abstract}

Novel coatings containing silver nanoparticles (AgNPs) with strong bonding and controllable antibacterial activity on polyamide 6,6 fabric were produced by dielectric barrier discharge (DBD) plasmaassisted deposition at atmospheric pressure and hexamethyldisiloxane (HMDSO) layers. Silver ion release was tuned using a "sandwich" coating structure to prolong the antibacterial effect. The novel spray-assisted deposition increased deposition rates of AgNPs using atmospheric pressure DBD plasma treatment when an HMDSO layer was applied. An increase in AgNPs deposition in plasma treated samples and antimicrobial activity against Gram-negative (Escherichia coli) for samples with an additional HMDSO layer was observed. These coatings allow the development of new and safe wound dressings able to switch the antimicrobial effect against Grampositive and Gram-negative bacteria by washing the dressing at high temperature $\left(75^{\circ} \mathrm{C}\right)$ before application.

Key Terms

Antimicrobial Textiles, DBD Plasma, Hexamethyldisiloxane, Silver Nanoparticles

\section{Introduction}

Medical textiles are used in a range of applications, from bandages, dressings, sutures, and surgical clothing to implants such as scaffolds, stents, and meshes. ${ }^{1}$ Infections associated with these devices are responsible for at least $2-7 \%$ of post-operational complications, increasing mortality and healthcare costs. ${ }^{2}$ Silver has been used as an antimicrobial agent for centuries, with the emergence of nanotechnology revealing new advantages for its use. Silver nanoparticles (AgNPs) present a large surface-volume area, improving the interaction with microorganisms and, consequently, enhancing the silver antimicrobial effect. ${ }^{3}$ Conventional antibacterial coatings by wet chemistry, lowpressure plasma, and sputtering have several drawbacks, but the most important is their uncontrollable antibacterial activity that can generate antimicrobial resistance. ${ }^{4}$ Additionally, AgNPs can pass through layers of the skin and accumulate in the body organs, promoting renal, hepatic and neurological disturbances ${ }^{5,6}$ Incorporating AgNPs in nanocomposites through synthetic polymers is a suitable alternative to obtain controllable AgNPs release. This technique allows more efficient AgNPs immobilization than that of a simple coating. ${ }^{7}$ Dielectric barrier discharge (DBD) plasma treatment at atmospheric pressure is an environmentally-friendly method to modify materials. This treatment can increase the surface energy by introduction of new polar functionality, enhancing the material's adhesion and wettability. ${ }^{8}$ This non-thermal plasma process is able to create charged molecular fragments and atomic species, promoting new reactions. ${ }^{9}$ Hexamethyldisiloxane (HMDSO) has been used as a suitable precursor to obtain coatings on metals. HMDSO is volatile at room temperature, non-toxic, non-flammable, inexpensive, and available from commercial sources. ${ }^{10}$

In this work, a new generation of coatings containing silver nanoparticles (AgNPs) was produced, using dielectric barrier discharge (DBD) plasma-assisted deposition at atmospheric pressure. Low concentrations of AgNPs dispersions in water and HMDSO were prepared and applied in different configurations, including a barrier layer of pristine HMDSO, to control AgNPs ion release. Reflectance measurements, static contact angle, scanning electron microscopy (SEM), energy dispersive spectroscopy (EDX), and X-ray photoelectron spectroscopy (XPS) were used to characterize the samples. Antibacterial activity was determined for both Grampositive 
Staphylococcus aureus (S. aureus) and Gram-negative Escherichia coli (E. coli) bacteria. The development of coatings with controllable release of silver ions would allow the development of a new generation of wound dressings using a very low but effective amount of silver nanoparticles, while avoiding the sensitization and metal accumulation problems that can occur with use of silver nanoparticles.

\section{Experimental}

\section{Materials}

Commercial polyamide 6,6 (PA6,6) fabric, with a weight per unit area of $110 \mathrm{~g} / \mathrm{m}^{2}$, warp density of 50 threads $/ \mathrm{cm}$, and a weft density of 32 threads/cm were used in this study. The fabric was pre-washed with $1 \mathrm{~g} / \mathrm{L}$ of a non-ionic detergent solution at $60^{\circ} \mathrm{C}$ for $60 \mathrm{~min}$, then rinsed with distilled water, and dried at $40^{\circ} \mathrm{C}$. All the other reagents were analytical grade purchased from SigmaAldrich (St. Louis, MO, USA) and used without further purification.

\section{Procedures}

\section{DBD Plasma Treatment}

DBD plasma treatment was performed in a semi-industrial plasma prototype machine (Softal $\mathrm{GmbH}$, University of Minho) working at room temperature (RT) and atmospheric pressure in air, using a system of metal electrode coated with ceramic and counter electrodes coated with silicon having a 50 -cm effective width, a gap distance fixed at $3 \mathrm{~mm}$, and producing the discharge at high voltage $(10 \mathrm{kV})$ and low frequency $(40 \mathrm{kHz})$. The discharge power supplied by the electrodes and the speed was variable, with a maximum discharge of $1.5 \mathrm{~kW}$ and speed of $60 \mathrm{~m} / \mathrm{min}$. The applied dosage on PA6,6 fabric was $5 \mathrm{~kW} \mathrm{~min} / \mathrm{m}^{2}$. The machine was operated at optimized parameters: $1 \mathrm{~kW}$ of power and a velocity of $4 \mathrm{~m} / \mathrm{min}$.

AgNPs Dispersions Preparation and PA6,6 Fabric Composites Preparation

Composites were obtained with $20 \mathrm{~nm}$ AgNPs using $10 \times 10 \mathrm{~cm}$ PA6,6 samples with and without DBD plasma treatment by spray. Water and HMDSO AgNPs dispersions $(10 \mu \mathrm{g} / \mathrm{mL})$ were prepared by sonication for $30 \mathrm{~min}$ in a Branson 3510 bath and $30 \mathrm{~min}$ in an Optic Ivymen Sytem CY-500 with a tip. The layers were applied on both sides with the spray system pressurized at 1.5 bar and maintained at a distance of $5 \mathrm{~cm}$ to

Table I.

PA6,6 Samples Developed with Different HMDSO Coating Layers

\begin{tabular}{|l|l|l|l|}
\hline Sample & 1st Layer & 2nd Layer & 3rd Layer \\
\hline AgNPs & Spray NPs in water & - & - \\
\hline AgNPs+HMDSO & Spray NPs in water & Spray HMDSO & - \\
\hline HMDSO+AgNPs+HMDSO & Spray HMDSO & Spray NPs in HMDSO & Spray HMDSO \\
\hline (HMDSO/AgNPs) & Spray NPs in HMDSO & - & - \\
\hline (HMDSO/AgNPs)+HMDSO & Spray NPs in HMDSO & Spray HMDSO & - \\
\hline
\end{tabular}

the substrate. The different structures developed are presented in Table I. A curing step was used between each layer. The samples were dried at $25^{\circ} \mathrm{C}$.

Washing Fastness

The washing fastness of samples was assessed after five washing cycles in a laboratory-dyeing machine (Ahiba, Datacolor, Lawrenceville, NJ, USA) at $75^{\circ} \mathrm{C}$ and $40 \mathrm{rpm}$ for $15 \mathrm{~min}$ with $0.1 \mathrm{~g} / \mathrm{L}$ of non-ionic surfactant at a liquor ratio (LR) of 1:30.

\section{Analytical Methods \\ Reflectance}

The samples with AgNPs were analyzed using a Datacolor Spectraflash SF 600 Plus CT spectrophotometer with $\mathrm{D}_{65}$ light, over the range of 390 to $700 \mathrm{~nm}$ and expressed in reflectance $(\% \mathrm{R})$. Reflectance measurements were made three times in different fabric positions and the average was calculated.

\section{Thermogravimetric Analysis}

TGA measurements were carried out on an STA 7200 Hitachi (Tokyo, Japan). TGA plots were obtained within the range of 25 to $900^{\circ} \mathrm{C}$ under nitrogen atmosphere $(200 \mathrm{~mL} / \mathrm{min})$ at 110 ${ }^{\circ} \mathrm{C} / \mathrm{min}$. Specimens were left at RT $\left(25^{\circ} \mathrm{C}\right)$ until equilibrium was reached and placed in an alumina pan. Data was plotted as weight loss percent versus temperature, and the mass of dried residues calculated for each case. Derivative thermogravimetric (DTG) analysis was also performed to identify the maximum peaks of the thermal transformation events.

\section{Contact Angle}

The water surface wettability of PA6,6 samples was characterized by static contact angle measurements based on the sessile drop principle using Dataphysics equipment (Filderstadt, Germany) and OCA20 software with a video system to capture images in static and dynamic modes. All experiments were replicated three times and the data were reported as mean \pm standard deviation.

\section{SEM and EDX}

Morphological analysis of fabrics were carried out using ultrahigh resolution field emission gun scanning electron microscopy (FEG-SEM, NOVA 200 Nano SEM, FEI Co.). Secondary electron images were performed with an acceleration voltage of $5 \mathrm{kV}$. Backscattering electron images were realized with an acceleration voltage of $15 \mathrm{kV}$. Samples were covered with a film of Au-Pd (80-20 $\mathrm{wt} \%$ ) in a high-resolution sputter coater (208HR, Cressington Co.), coupled to an MTM-20 Cressington high-resolution thickness controller. Atomic compositions of the membrane were examined with the energy dispersive spectroscopy (EDX) capability of the SEM equipment using an EDAX $\mathrm{Si}(\mathrm{Li})$ detector and an acceleration voltage of $5 \mathrm{kV}$. 


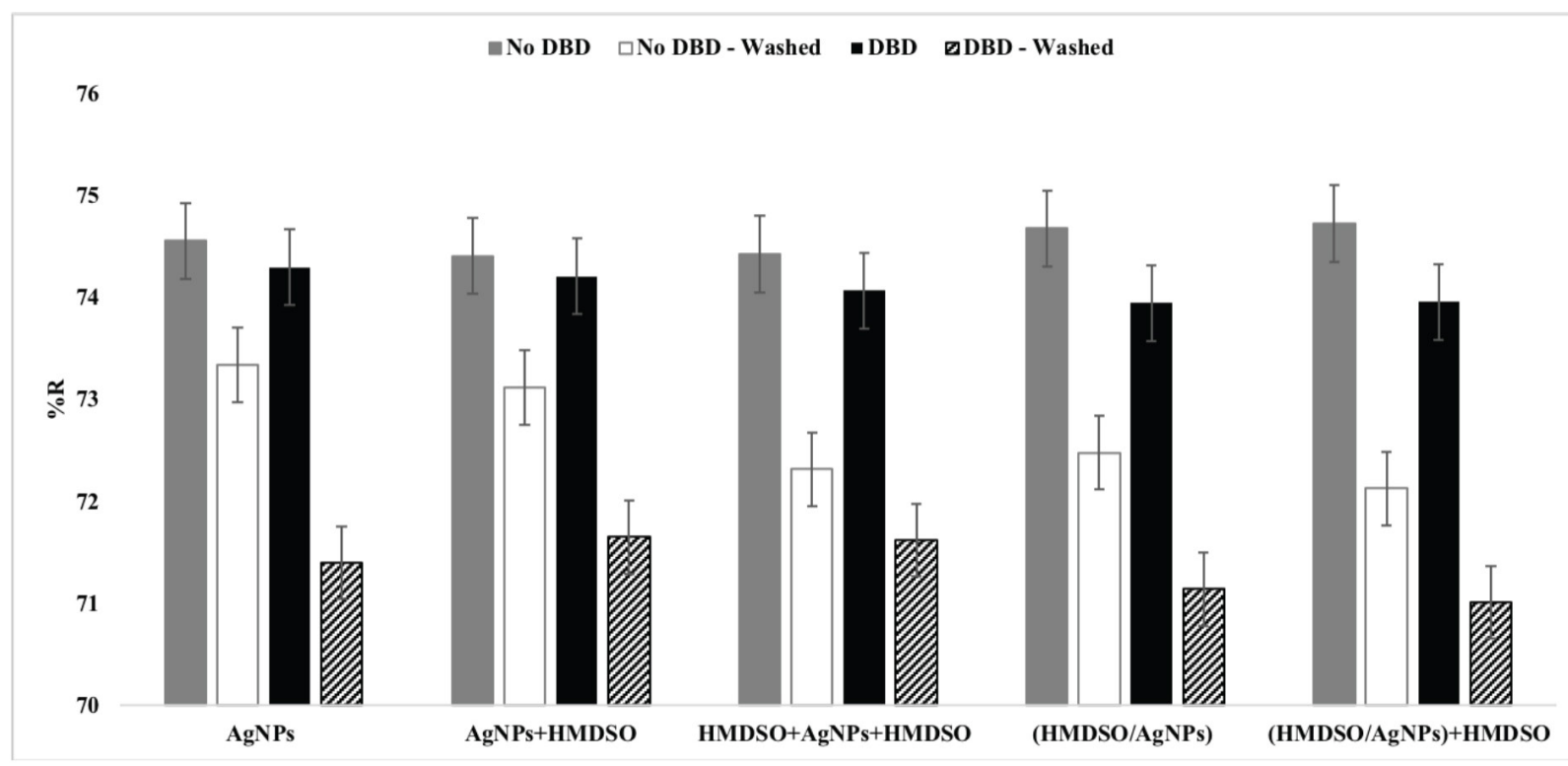

Fig. 1. Reflectance measurements at $420 \mathrm{~nm}$ of untreated and DBD plasma treated PA6,6 samples with AgNPs obtained by spray before and after five washing cycles.

XPS

XPS analyses were performed using a Kratos AXIS Ultra HSA, with Vision software for data acquisition and CasaXPS software for data analysis. The analysis was carried out on a monochromatic $\mathrm{Al} \mathrm{K \alpha}$ X-ray source $(1486.7 \mathrm{eV})$ operating at $15 \mathrm{kV}(150 \mathrm{~W})$, in fixed analyzer transmission (FAT) mode, with a pass energy of $40 \mathrm{eV}$ for regions ROI and 80 $\mathrm{eV}$ for survey. Data was acquired at a pressure less than $1 \times$ $10^{-6} \mathrm{~Pa}$, and a charge neutralization system was used. Spectra were charge corrected to give the $\mathrm{C} 1 \mathrm{~s}$ spectral component (C-C and $\mathrm{C}-\mathrm{H}$ ) a binding energy of $285 \mathrm{eV}$. High-resolution spectra were collected using an analysis area of $\sim 1 \mathrm{~mm}^{2}$. The peaks were constrained to have equal FWHM to the main peak. This process has an associated error of $\pm 0.1 \mathrm{eV}$. Spectra were analyzed for elemental composition using CasaXPS software (version 2.3.15). Deconvolution into subpeaks was performed by least-squares peak analysis software, XPSpeak version 4.1, using the Gaussian/Lorenzian sum function and Shirley-type background subtraction. No tailing function was considered in the peak fitting procedure. The components of the various spectra were mainly modelled as symmetrical Gaussian peaks, unless a certain degree of Lorentzian shape was necessary for the best fit. The best mixture of GaussianLorentzian components was defined based on the instrument and resolution (pass energy) settings used, as well as the natural line width of the specific core hole.

\section{Antimicrobial Analyses}

Antibacterial testing was performed with a slightly modified ISO 20743-2005 standard for the determination of the antibacterial activity of textiles, immediately after sample preparation. PA6,6 samples ( $0.05 \mathrm{~g})$ were used. The samples (initial, washed and control samples), were placed in 24-well cell culture plates. On each of the samples, $50 \mu \mathrm{L}$ of the $10^{5}$ $\mathrm{CFU} / \mathrm{mL}$ bacterial inoculum was deposited. S. aureus (ATCC 25923) and E. coli (ATCC 25922) were used. After $24 \mathrm{~h}$ of incubation time at $37^{\circ} \mathrm{C}$, samples were aseptically transferred to a Falcon tube containing $5 \mathrm{~mL}$ of TSB medium and bacteria were removed from samples using a VibraMix shaker at 2000 $\mathrm{rpm}$. This suspension was used to prepare 10 -fold serial dilutions, which were plated out for the determination of viable counts. The number of CFUs was counted before $(0 \mathrm{~h})$ and after (6h) of contact with the fabrics. The results were expressed as log reduction, calculated as the ratio between the number of surviving bacteria colonies present on the TSA plates, before and after contact with the fabric. The antibacterial activity was determined in triplicates in two independent experiments.

\section{Results and Discussion}

\section{Quantification of AgNPs on PA6,6 Samples by Diffuse Reflectance Spectroscopy}

Since the nanoparticles and the HMDSO coatings have a negligible weight, reflectance measurements were performed to characterize the samples containing AgNPs and HMDSO layers in terms of AgNPs relative concentration (Fig. 1). ${ }^{12}$ Following the principle that silver nanoparticles are able to absorb light in the visible spectra, the reflectance values indicate the relative amount of AgNPs on a sample. Thus, the AgNPs concentration was inversely proportional to reflectance measurements. A low reflectance percentage indicated a high AgNPs concentration on the fabric. ${ }^{13}$ 
The UVVis spectrum of $20 \mathrm{~nm}$ PVP-AgNPs showed the maximum absorbance value at $420 \mathrm{~nm}$, and therefore just this wavelength was used. ${ }^{14}$ The results show that DBD plasma treatment decreased the reflectance values in all tested samples. The effect was more noticeable for the AgNPs dispersed in HMDSO (HMDSO/AgNPs). The untreated PA6,6 samples displayed similar reflectance values regardless of the solvent and the configuration of the layers used. The improvement in AgNPs adhesion promoted by DBD plasma treatment and the HMDSO layer can be attributed to increased surface roughness and chemical modification of the surface (e.g., oxygen addition). Several reports have shown microroughness formation during the DBD plasma treatment due to the etching process that could promote the anchorage of carboxylic groups. ${ }^{15,16}$ The deposition of HMDSO using air as a carrier gas increased inorganic silicon dioxide formation, which also increased the surface roughness. ${ }^{10}$ AgNPs dispersions prepared in HMDSO tend to agglomerate. However, the silicon dioxide coating after deposition also supports AgNPs adhesion onto textile materials. ${ }^{17}$ After five washing cycles, the reflectance values decreased in all samples, but was more evident in DBD plasma-treated samples. These results were not comparable with the unwashed samples. The sharp decrease in reflectance was attributed to the change in the silver oxidation state due to the washing process and to the reaction of metallic silver and silver ions with plasma-generated oxygen reactive species. Oxidized silver (e.g., $\mathrm{AgO}$ and $\mathrm{Ag}_{2} \mathrm{O}$ ) display larger absorption bands than metallic silver. ${ }^{18,19}$

\section{Static Contact Angle}

The contact angle of samples without and with DBD plasma treatment were measured to analyze the fabrics wettability (Table II). Both the surface chemical composition and the surface morphology interfere with wettability properties of a solid surface. ${ }^{16}$ Samples with DBD plasma treatment showed a smaller contact angle under all conditions tested, suggesting more roughness and polar groups in the surface of plasma treated samples as explained above. Despite the change in surface topography, and because DBD plasma is a surface treatment, no changes in the mechanical properties can be observed in the PA6,6 fabric, as shown in previous

\begin{tabular}{|l|l|l|}
\hline \multicolumn{3}{|l|}{$\begin{array}{l}\text { Table II. } \\
\text { Static Contact Angle of PA6,6 Samples with Various HMDSO Layers }\end{array}$} \\
\hline & No DBD & DBD \\
\hline AgNPs & $78.2 \pm 4.31$ & $53.0 \pm 3.47$ \\
\hline AgNPs+HMDSO & $81.0 \pm 2.90$ & $64.5 \pm 1.34$ \\
\hline HMDSO+AgNPs+HMDSO & $78.0 \pm 0.71$ & $71.2 \pm 0.57$ \\
\hline (HMDSO/AgNPs) & $81.1 \pm 4.80$ & $75.5 \pm 4.38$ \\
\hline (HMDSO/AgNPs)+HMDSO & $107.7 \pm 2.97$ & $97.1 \pm 4.67$ \\
\hline
\end{tabular}
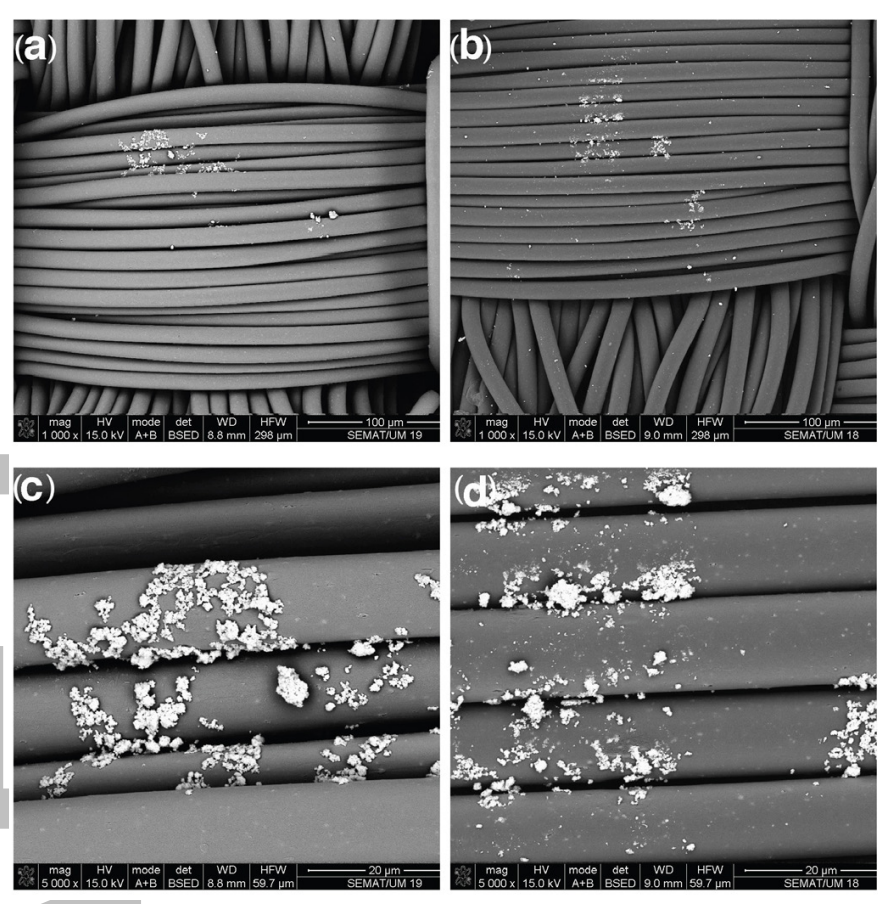

Fig. 2. SEM micrograph at $1000 \times$ and $5000 \times$ of untreated $(a, c)$ and plasma treated (b,d) PA6,6 fabrics.

work. ${ }^{13,20}$ Nevertheless, a thermogravimetric analysis was performed and no significant differences were observed (data available from author upon request).

\section{SEM and EDX Topography Analysis}

SEM analyses of untreated and DBD plasma treated PA6,6 samples were performed at different magnifications to analyze the AgNPs distribution from the different tested methods. In this work, data for AgNPs+HMDSO with and without DBD plasma treatment are shown (Fig. 2), although all samples demonstrated retention of AgNPs on the surface. Despite the very small concentration of AgNPs used in this work, SEM images were able to confirm the presence of AgNPs on the fabric surface and a slight improvement in the nanoparticle distribution by plasma treatment (Figs. $2 \mathrm{~b}$ and d). However, SEM analysis was not able to demonstrate if plasma treatment was able to improve the loading of nanoparticles on the fabric. For this reason, reflectance and XPS spectroscopic analyses were also performed.

EDX analysis of the AgNPs+HMDSO sample showed silver peaks (Fig. 3), however very similar results were obtained for all other samples because of the deep probe depth of the EDX technique. The characteristics peaks of silver (AgLI, $\mathrm{AgLa}, \mathrm{AgLb}$, and $\mathrm{AgLg}$ ) were observed in the EDX spectrum between 2.5 and $3.4 \mathrm{keV}$. Other elements were detected in the EDX spectra such as carbon, oxygen, and silicon, corresponding to PA6,6 atomic components, DBD plasma treatment, and HMDSO layers. 


\begin{tabular}{|c|c|c|c|c|c|c|c|c|}
\hline \multirow[t]{2}{*}{ Samples } & \multicolumn{4}{|c|}{ No DBD } & \multicolumn{4}{|l|}{ DBD } \\
\hline & $\begin{array}{l}\text { O } \\
\text { (at.\%) }\end{array}$ & $\begin{array}{l}\mathrm{C} \\
\text { (at.\%) }\end{array}$ & $\begin{array}{l}\mathrm{N} \\
\text { (at.\%) }\end{array}$ & $\begin{array}{l}\mathbf{A g} \\
\text { (at.\%) }\end{array}$ & $\begin{array}{l}\text { O } \\
\text { (at.\%) }\end{array}$ & $\begin{array}{l}\mathrm{C} \\
\text { (at.\%) }\end{array}$ & $\begin{array}{l}\mathrm{N} \\
\text { (at.\%) }\end{array}$ & $\begin{array}{l}\text { Ag } \\
\text { (at.\%) }\end{array}$ \\
\hline AgNPs & 11.2 & 80.1 & 8.6 & 0.1 & 12.5 & 77.0 & 9.0 & 1.5 \\
\hline AgNPs+HMDSO & 10.2 & 82.0 & 7.8 & n.d. & 12.8 & 79.2 & 8.0 & n.d. \\
\hline HMDSO+AgNPs+HMDSO & 10.3 & 81.8 & 7.9 & n.d. & 13.8 & 77.7 & 8.5 & n.d. \\
\hline (HMDSO/AgNPs) & 9.6 & 81.6 & 7.7 & 1.1 & 12.9 & 75.8 & 6.0 & 5.3 \\
\hline $\begin{array}{l}\text { (HMDSO/ } \\
\text { AgNPs)+HMDSO }\end{array}$ & 10.1 & 82.0 & 7.9 & n.d. & 14.1 & 77.3 & 8.6 & n.d. \\
\hline
\end{tabular}

\section{XPS Analysis}

XPS analysis was used to detect the surface atomic percentage of oxygen, carbon, nitrogen, and silver in the samples (Table III). Samples with DBD plasma treatment showed greater oxygen content in all tested samples. This can be explained by the new groups produced by DBD plasma treatment. Silver was only detected in the samples without an extra HMDSO layer such as AgNPs in water and (HMDSO/AgNPs) due to the surface nature of the XPS analysis technique. In samples with DBD plasma treatment, the silver content was

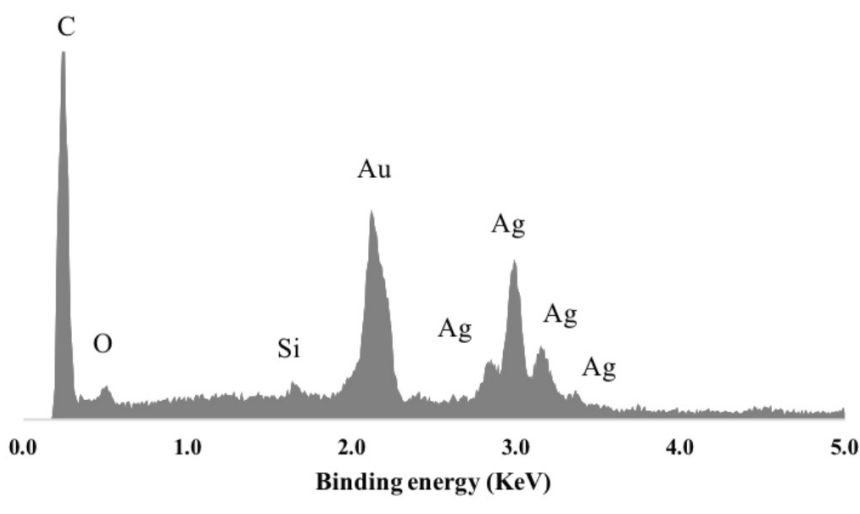

Fig. 3. EDX analysis of AgNPs+HMDSO PA6,6 sample with DBD plasma treatment. significantly higher (1.5 and 5.3 at.\%) than untreated samples (0.1 and 1.0 at.\%). Additionally, the AgNPs dispersed in HMDSO also suggest an improvement in nanoparticle deposition. The samples with an additional HMDSO layer (AgNPs+HMDSO and (HMDSO/AgNPs)+HMDSO) did not show silver peaks, confirming the protection ability of the HMDSO barrier layer upon the layer containing AgNPs.

\section{Antimicrobial Activity}

Antibacterial activity of PA6,6 samples was evaluated against $S$. aureus and E. coli bacteria before and after five washing cycles (Fig. 4). The antimicrobial activity of AgNPs is dependent on various factors, including the type of capping agent, concentration, size, shape, oxidation state of silver, conditions, and medium. XPS analysis (Table III) shows that there was no AgNPs on the surface for all samples with HDMSO as the top layer. However, antibacterial activity was (a)

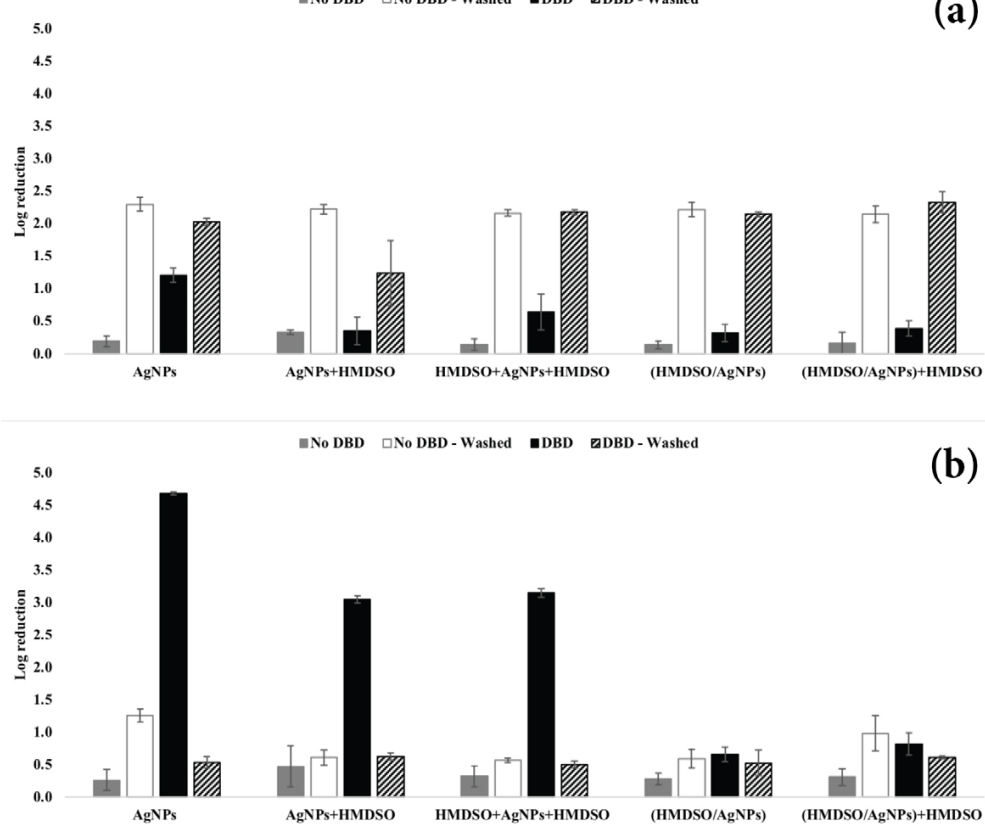
observed for DBD plasma treated samples using AgNPs in water without HMDSO layers (log reduction of $4.68 \pm 0.02$ ), and AgNPs+HMDSO and (HMDSO+AgNPs)+HMDSO samples ( $\log$ reductions of $3.04 \pm 0.06$ and $3.15 \pm 0.07$ ) (Fig. 4b) against E. coli. The other sample with premixed HDMSO and AgNPs, despite the improved loading of AgNPs detected by XPS analysis, showed very low antimicrobial activity and no significant difference using DBD plasma treatment. It seems that the silicon porous structure of HMDSO inhibits AgNPs oxidation and the release of $\mathrm{Ag}^{+}$ions, reducing the antimicrobial activity. Silicon and silicon dioxide structures have been previously used as a carrier for controlled drug delivery applications owing to its porous structure. ${ }^{21}$ Plasma treatment was able to tightly maintain nanoparticles on the fabric surface and provide the right oxidative environment for the formation and release of $\mathrm{Ag}^{+}$ions that are then delayed by the HMDSO layer as previously observed. ${ }^{22}$ It is also important that the concentra-

Fig. 4. Antimicrobial activity against $S$. aureus $(A)$ and $E$. coli (\$) with different HMDSO coatings layers before and after five washing cycles.
Ition of AgNPs was very low, at least ten times less than usually 
found in the literature. Despite that, the DBD plasma treated samples showed antibacterial activity, even when this low AgNPs concentration was used. In fact, DBD plasma treatment in air produces several biologically reactive species, particularly ROS, that can also interact with the biological target. ${ }^{23-25}$

After washing, the antimicrobial effect on $S$. aureus for both untreated and DBD plasma treated samples showed a significant increase (log reduction between 1.5 and 2.3), while $E$. coli showed a log reduction decrease. The particular increase in $\log$ reduction values for $S$. aureus can be ascribed to the change of the AgNPs oxidation state during the washing process. ${ }^{26}$ These results suggested a method of switching the antimicrobial effect against E. coli and S. aureus in the same wound dressing before application.

\section{Conclusions}

The results obtained in this study demonstrated the enhancement of AgNPs adhesion when roughened surfaces and newly reactive oxygen species are provided by DBD plasma treatment and HMDSO deposition, allowing the development of antimicrobial wound dressings using very low concentrations of AgNPs. A final HMDSO layer to control the release of AgNPs and $\mathrm{Ag}^{+}$ions was effective against E. coli. A washing step at $75^{\circ} \mathrm{C}$ switched the antimicrobial effect, improving the S. aureus antimicrobial activity, probably due to the change of the oxidative state of silver.

\section{Acknowledgements}

This work was funded by European Regional Development funds (FEDER) through the Competitiveness and Internationalization Operational Program (POCI) - COMPETE and by National Funds through Portuguese Fundação para a Ciência e Tecnologia (FCT) under the project UID/ CTM/00264/2019. Ana Ribeiro acknowledges FCT for its doctoral grant SFRH/BD/137668/2018. Andrea Zille also acknowledges financial support of the FCT through an Investigator FCT Research contract (IF/00071/2015) and the project PTDC/CTM-TEX/28295/2017 financed by FCT, FEDER, and POCI in the frame of the Portugal 2020 program.

\section{References}

1. Radetić, M. Journal of Photochemistry and Photobiology C: Photochemistry Reviews 2013, 16, 62-76.

2. Deng, X.; Leys, C.; Vujosevic, D.; Vuksanovic, V.; Cvelbar, U.; De Geyter, N.; Morent, R.; Nikiforov, A. Plasma Processes and Polymers 2014, 11 (10), 921-930.

3. Montagut, A. M.; Granados, A.; Ballesteros, A.; Pleixats, R.; Llagostera, M.; Cortés, P.; Sebastián, R. M.; Vallribera, A. Tetrahedron 2019, 75 (1), 102-108.

4. Simoncic, B.; Tomsic, B. Textile Research Journal 2010, 80 (16), 1721-1737.

5. Hadrup, N.; Sharma, A. K.; Loeschner, K. Regulatory Toxicology and Pharmacology 2018, 98, 257-267.
6. Wagener, S.; Dommershausen, N.; Jungnickel, H.; Laux, P.; Mitrano, D.; Nowack, B.; Schneider, G.; Luch, A. Environmental Science \& Technology 2016, 50 (11), 5927-5934.

7. Hassabo, A. G.; El-Naggar, M. E.; Mohamed, A. L.; Hebeish, A. A. Carbohydrate Polymers 2019, 210, 144-156.

8. Ribeiro, A. I.; Senturk, D.; Silva, K. S.; Modic, M.; Cvelbar, U.; Dinescu, G.; Mitu, B.; Nikiforov, A.; Leys, C.; Kuchakova, I.; Vanneste, M.; Heyse, P.; De Vrieze, M.; Souto, A. P.; Zille, A. IOP Conference Series: Materials Science and Engineering 2018, 460, 012007.

9. Morent, R.; De Geyter, N.; Van Vlierberghe, S.; Dubruel, P.; Leys, C.; Gengembre, L.; Schacht, E.; Payen, E. Progress in Organic Coatings 2009, 64 (2-3), 304-310.

10. Alissawi, N.; Peter, T.; Strunskus, T.; Ebbert, C.; Grundmeier, G.; Faupel, F. Journal of Nanoparticle Research 2013, 15 (11), 2080.

11. Oliveira, F. R.; Souto, A. P.; Carneiro, N.; Nascimento, J. H. O. Materials Science Forum 2010, 636-637, 846-852.

12. Silva, I. O.; Ladchumananandasivam, R.; Nascimento, J. H. O.; Silva, K. S.; Oliveira, F. R.; Souto, A. P.; Felgueiras, H. P.; Zille, A. Nanomaterials 2019, 9 (8), 1064.

13. Zille, A.; Fernandes, M. M.; Francesko, A.; Tzanov, T.; Fernandes, M.; Oliveira, F. R.; Almeida, L.; Amorim, T.; Carneiro, N.; Esteves, M. F.; Souto, A. P. ACS Appl. Mater. Inter. 2015, 7 (25), 13731-13744.

14. Bhatia, D.; Mittal, A.; Malik, D. K. 3 Biotech 2016, 6 (2), 196.

15. Rezaei, F.; Shokri, B.; Sharifian, M. Applied Surface Science 2016, 360, 641-651.

16. Gao, M.; Sun, L.; Guo, Y.; Shi, J.; Zhang, J. Chemical Physics Letters 2017, 689, 179-184.

17. Sotiriou, G. A.; Teleki, A.; Camenzind, A.; Krumeich, F.; Meyer, A.; Panke, S.; Pratsinis, S. E. Chemical Engineering Journal 2011, 170 (2-3), 547-554.

18. Al-Kuhaili, M. F. Journal of Physics D: Applied Physics 2007, 40 (9), 2847-2853.

19. Inácio, P. L.; Barreto, B. J.; Horowitz, F.; Correia, R. R. B.; Pereira, M. B. Optical Materials Express 2013, 3 (3), 390.

20. Ribeiro, A. I.; Senturk, D.; Silva, K. S.; Modic, M.; Cvelbar, U.; Dinescu, G.; Mitu, B.; Nikiforov, A.; Leys, C.; Kuchakova, I.; Vanneste, M.; Heyse, P.; De Vrieze, M.; Souto, A. P.; Zille, A. IOP Conference Series: Materials Science and Engineering 2018, 460.

21. Kim, T.; Braun, G. B.; She, Z.-G.; Hussain, S.; Ruoslahti, E.; Sailor, M. J. ACS Appl. Mater. Inter. 2016, 8 (44), 30449-30457.

22. Alissawi, N.; Peter, T.; Strunskus, T.; Ebbert, C.; Grundmeier, G.; Faupel, F. Journal of Nanoparticle Research 2013, 15 (11).

23. Koduru, J. R.; Kailasa, S. K.; Bhamore, J. R.; Kim, K.-H.; Dutta, T.; Vellingiri, K. Advances in Colloid and Interface Science 2018, 256, 326-339.

24. Lin, A.; Gorbanev, Y.; De Backer, J.; Van Loenhout, J.; Van Boxem, W.; Lemière, F.; Cos, P.; Dewilde, S.; Smits, E.; Bogaerts, A. Advanced Science 2019, 6 (6), 1802062.

25. Arjunan, K. P.; Friedman, G.; Clyne, A. M. ASME 2011 Summer Bioengineering Conference, Parts A and B, Farmington, PA, USA, 2011, pp 611-612.

26. Archana, D.; Singh, B. K.; Dutta, J.; Dutta, P. K. International Journal of Biological Macromolecules 2015, 73, 49-57.

\section{Author}

Andrea Zille, 2C2T-Centro de Ciência e Tecnologia Têxtil, University of Minho, Guimarães, Portugal; phone +35.1253.510285; fax +35.1253.510293; azille@2c2t.uminho.pt. 